\title{
LOKATIIVSETE DEMONSTRATIIVADVERBIDE ASETUSEST JA FUNKTSIOONIDEST LIIKUMIST VÄLJENDAVATE KLAUSIDE NÄITEL
}

\author{
PIIA TAREMAA
}

$\mathrm{D}$ emonstratiividel, nagu näiteks see ja siin, on oluline koht keeles. Seetõttu on demonstratiivid maailma keeleteaduses eri vaatenurkadest pälvinud võrdlemisi suurt tähelepanu (vt nt Fillmore 1975, 1997; Lyons 1977; Karmiloff-Smith 1979; Clark jt 1983; Levinson 1983; Gundel jt 1993; Laury 1997; Diessel 1999a, 1999b, 2006; Dixon 2003; Enfield 2003; Kemmerer 2006; Coventry jt 2008; Leu 2008; Halliday, Hasan 2013; Stevens, Zhang 2013; Peeters jt 2015). Eesti keeleteaduses on demonstratiive palju uurinud Renate Pajusalu (1999, 2004, 2005, 2015, 2017b), nagu ka mitmed teised (nt Sahkai 1999, 2003, 2016; Vija 2007; Kaiser, Vihman 2010; Keevallik 2011; Soodla jt 2012; Hint jt 2013; Eslon 2014; Reile 2015, 2016; Tammekänd 2015).

Demonstratiive puudutavad uurimused keskenduvad suures osas pigem demonstratiivpronoomenite (nagu eesti keele see) kasutusele. Demonstratiivadverbe, lokatiivseid demonstratiivadverbe sealhulgas (nagu siin ja seal), on palju vähem käsitletud nii maailma kui ka eesti keeleteaduses. Siinne artikkel vaatleb just lokatiivsete demonstratiivadverbide kasutust eesti keeles, keskendudes nende funktsioonidele ning asendile klausis teiste keeleüksuste suhtes. Analüüsitav keelematerjal esindab üht kitsamat tähendusvaldkonda, kus ruumilised suhted on eriti olulised ning seetõttu hästi jälgitavad ka demonstratiivadverbide kasutuse kaudu. See valdkond on liikumine. Kirjeldatav materjal pärineb eesti kirjakeele korpustest.

\section{Eesti keele lokatiivsete demonstratiivadverbide funktsioonidest}

Eesti grammatikates on lokatiivseid demonstratiivadverbe siin ja seal (ning nende vorme) pikalt käsitletud mitte eraldi sõnaklassina, vaid lihtsalt (koha)adverbidena (vt nt Tauli 1973: 113-115; Veski 1982: 7-11). EKG-s (I: 32) käsitletakse neid aga eraldi sõnaklassi ehk proadverbidena (vt ka Erelt 2017a: 59-60). Mati Erelt (2000: 12-13) on nimetanud neid ka demonstratiivseteks proadverbideks.

Nagu enamikul kohaadverbidel, on ka lokatiivsetel demonstratiivadverbidel kolmevormilised sarjad - siit, siin, siia; sealt, seal, sinna (Veski 1982: 7-11, 46) -, mis on ajalooliselt näitava asesõna see muutevormid või temast moodustatud tuletise muutevormid (EES: 463). Lisaks esinevad need kuus vormi liitadverbide eesosana (nt siiapoole) ning ka paarissõnaliste adverbidena (nt siin-seal) (Veski 1982: 46-47).

Demonstratiivadverbide puhul on välja toodud nii nende semantilist funktsiooni kui ka tekstiehituslikku n-ö asendusfunktsiooni (Erelt 2000: 12-13; Eslon 2014: 24-25). Nii näiteks kirjeldab EKG, et lokatiivsete demonstratiiv- 
adverbide üks rolle on osaleda lausetevahelises asenduses asendusvormina, nt Ta läks välja, kuid tuli sealt kohe tagasi (EKG II: 206). Kuna demonstratiivide puhul ei pruugi asendamisest rääkimine olla kõige õigustatum, on keeleteaduses tavalisem demonstratiivadverbide kasutuse tõlgendamine tekstisisese viitamise või samaviitelisusena (vt ka Pajusalu 1999: 16; Keevallik 2011), kus demonstratiivadverb võib anafoorses kasutuses olla samaviiteline diskursuses eelnevalt esineva viitevahendiga või katafoorses kasutuses diskursuses järgneva viitevahendiga.

Lokatiivsetel demonstratiivadverbidel on ka ruumisemantiline mõõde, kuigi ruumilisele referendile viitamine võib olla nii mõnelgi juhul üsna abstraktne (vrd seal majas ja seal teoorias; vt ka Pajusalu 2005: 127-129, 2017b: 571-581). Nagu lokaaladverbid sageli, võivad lokatiivsed demonstratiivadverbid semantiliselt väljendada LÄHTEKOHTA ja LÄHTESUUNDA (nt sealt), TOIMUMISKонтA (nt seal) või SIHTKонтA ja SUUNDA (nt sinna), liitsõna osisena näitavad nad ka ruumilist piiri (nt sinnamaani ${ }^{1}$ ) või liikumisteed (nt sealtkaudu) (EKG I: 23; EKG II: 296-297; Veismann, Erelt 2017: 422-423). Lisaks kasutatakse lokatiivseid demonstratiivadverbe näiteks põimlausetes, kus nad funktsioneerivad korrelaatidena (nt läksin sinna, kuhu...)2.

Demonstratiividel on siiski ka muid tähtsaid funktsioone peale tekstisisese viitamise, samaviitelisuse märkimise ning lausele ruumisemantilise mõõtme andmise, näiteks võivad nad käituda artiklilaadselt (Pajusalu 1997, 1999) või olla olulised elemendid kõne planeerimisel, ka on neil informatsioonistruktuurilisi ülesandeid (Sahkai 2003, 2016; Keevallik 2011).

\section{Lokatiivsete demonstratiivadverbide lausemustritest eesti keeles}

Süntaktiliselt ning puhtvormiliselt võiks demonstratiivadverbe lauses pidada kohamäärusteks, nagu seda on tehtud eesti grammatikates (EKG II: 60-61). Kohamäärused (või kui rääkida sõnaliikidest, siis kohaadverbid) omakorda võivad vormi poolest olla separatiivsed, lokatiivsed või latiivsed, väljendades vastavalt LÄнтеконтА, тоIмUмIsконтА või sінтконтА (EKG II: 61; Veismann jt 2017: 326-337). Kuigi adverbifraasid võivad talitleda ka fraasiadverbiaalina (nt väga kaugel), ei ole demonstratiivadverbe tavaliselt nii tõlgendatud (vrd seal kaugel). Grammatikate järgi võiks demonstratiivadverbid moodustada omaette adverbifraasi, mitte olla adverbifraasi laiendid (EKG II: 136).

Demonstratiivadverbidel võib süntaktilises mõttes näha muidki funktsioone peale kohamääruse vormistamise. Näiteks nimisõna ees paiknedes ning nimisõnafraasiga sama ruumisuhet väljendades on Pajusalu $(1997,1999)$ järgi lokatiivsetel demonstratiivadverbidel artiklilaadne funktsioon. See tähendab, et demonstratiivadverbil on mitte niivõrd viitamisfunktsioon, vaid referendi definiitsuse märkimise roll, nagu lauses aga mismoodi sa Draamas ostsid need piletid sinna väiksesse saali3 ${ }^{3}$, kus demonstratiivadverbi ja nimisõnafraasiga väljendatakse eelnevas diskursuses fraasiga Draamas juba tutvustatud ruumi (Pajusalu 1997: 166-171).

\footnotetext{
${ }^{1}$ Ruumilist piiri näitavad ka adverbide siin ja seal terminatiivivormid siiani ja sinnani.

${ }^{2}$ Varasema käsitluse järgi on sel juhul tegu adverbiaallausete ehk nn kohalausetega (EKG II: 296-297). Uuema arusaama järgi on tegu kohamääruslike relatiivlausetega (Erelt 2017c: 667-669, 695-696, 738-750; Veismann jt 2017: 326).
}

${ }^{3}$ Näitelause Pajusalult (1997: 167). 
Sama ruumisuhet väljendades, kuid mitte tingimata nimisõnafraasi ees paiknedes, võib lokatiivsetel demonstratiivadverbidel olla lisandi omadusi, sest demonstratiivadverb justkui täpsustab ruumifraasiga (siinkohal kaassõnafraasiga) väljendatud informatsiooni (nt seal metsa all). Samas võiks öelda, et hoopis ruumifraas täpsustab demonstratiivadverbiga väljendatut. Niisiis oleks seejuures keeruline määrata, kas lisandi omadusi kannab demonstratiivadverb või ruumifraas, kuna ei ole üheselt selge, kumb kumba täpsustab. Lisandiks ei lubaks demonstratiivadverbi ega ka nimisõna-/kaassõnafraasi lugeda siiski asjaolu, et süntaktiline lisand peab olema „substantiiv(ifraas) või substantiivselt talitlev muu sõnaliigi sõna või fraas" (EKG II: 123); ta peab põhjaga olema „omavahel grammatiliselt seotud” ning moodustama koos põhjaga „kõrgema tasandi nimisõnafraasi” (Pajusalu 2017a: 392). Seetõttu võiks lokatiivseid demonstratiivadverbe sellistes konstruktsioonides, kui neid üldse selles valguses analüüsida, pidada apositiivseteks ehk lisandilaadseteks üksusteks, mis on defineeritud mis tahes süntaktiliste üksustena, „mis täpsustavad või seletavad eelnevalt väljendatut" (EKG II: 122; vt ka Pajusalu 2017a: 403). Lisandiks lubaks selliseid ühendeid tinglikult pidada aga see, et eesti keele demonstratiivadverbidel siin ja seal on piiratud muuteparadigmad. See teeb demonstratiivadverbid mõneti sarnaseks käändsõnaliste laienditega, kuna nimisõnafraasi ees paiknedes ning samale ruumisuhtele viidates avaldub semantiline ühildumine ka vormiliselt (vrd sealt majast, seal majas ja sinna majja).

Demonstratiivadverbide kasutust on peetud ka topeldamiseks, mille järgi demonstratiivadverb ja muu ruumiväljend kombineeruvad mitte alistussuhte järgi, vaid mõlemad on teatud määral teineteise vormist sõltumatud (Sahkai 2003). Selle kinnituseks on Heete Sahkai (2003) toonud välja asjaolu, et ruumiväljend ja demonstratiiv võivad asetseda teineteise suhtes eri moel: demonstratiivadverb võib näiteks esineda ruumiväljendist nii vasakul kui ka paremal (nt siin majas ja majas siin); samuti võivad nad lauses olla teineteisest muude keeleüksustega eraldatud (nt siin kõndis ta majas ringi).

Sõnajärje poolest on demonstratiivadverbe (või üldse adverbe) sisaldavaid lauseid eesti keeles siiski üsna vähe uuritud (vt ka Eslon 2014: 15, 43). Tavaline, neutraalne sõnajärg lauses on määruste puhul verb-adverbiaal; sõnajärg adverbiaal-verb esineb sel juhul, kui rõhutatakse adverbiaali, verbi või subjekti, ning kui kasutatakse modaaladverbi, siis ka kõneleja suhtumist (Tauli 1983: 153-154). Ka demonstratiivadverbide kohta võib näiteks Sahkai (1999: 28-30) uurimusest järeldada, et need asetsevad lause lõpu poole ning verbist paremal. Sõnajärg sõltub muidugi ka teistest võimalikest lauseliikmetest ja sõnavormidest lauses, näiteks infinitiivi esinemisest (Tauli 1983: 154-161), samuti lihtlause või liitlause tüübist (EKG II: 275-322) ning infostruktuurilistest ja muudest pragmaatilistest faktoritest (EKG II: 191-197; Lindström 2005, 2017).

On siiski üsna vähe teada, kuivõrd sarnane või erinev on demonstratiivadverbide ja teiste kohamäärusena esineda võivate keeleüksuste kasutus. Pille Eslon on näiteks adverbi sisaldavate kolmeliikmeliste sõnaühendite (ehk trigrammide) uurimisel leidnud, et kui trigrammi järjestus on adverb-adverbverb (tavaliselt koopulaverbiga olema), esineb esimese adverbina sagedasti proadverbe, sh lokaalseid proadverbe (ehk lokatiivseid demonstratiivadverbe, nt seal all on) (Eslon 2014: 22-23). See annab tunnistust, et lokatiivsed demonstratiivadverbid võivad käituda teistmoodi kui kohamäärused tavaliselt ning et ka nende omavaheline paigutus ei ole juhuslik. 


\section{Eesmärk ja uuritav keelematerjal}

Siinse analüüsi eesmärk on kirjeldada demonstratiivadverbide siin ja seal (ning nende vormide siit, siia ja sealt, sinna) kasutust eesti keeles ühe kitsamalt defineeritud tähendusvaldkonna - liikumise - näitel. Analüüsis kasutatav materjal pärineb siinkirjutaja uurimistöö andmestikust (Taremaa 2017) eesti keele liikumisklauside kohta (kokku 9500 füüsilist liikumist väljendavat klausi), mis omakorda on liikumisverbide järgi (iga verbiga $(n=95) 100$ klausi) võetud eesti kirjakeele korpustest (http://cl.ut.ee/korpused/): tasakaalus korpuse ilukirjanduse allkorpusest (lausenäited lühendiga IK) ning segakorpuse ajakirjanduse allkorpustest (lausenäited lühendiga AK; materjali kohta vt täpsemalt Taremaa 2017: 74-87). Lokatiivseid demonstratiivadverbe (st siit, siin, siia, sealt, seal, sinna) esines 9500 liikumisklausist 229 klausis $(2,4 \%)$, mis moodustavadki siinse uurimuse materjali. Lisaks neile 229 klausile oli materjalis 22 klausi, kus lokatiivset demonstratiivadverbi oli kasutatud liitsõna eesosana (nt siiapoole), ent neid siinne analüüs ei kajasta - artikkel keskendub ainult mitteliitsõnalistele demonstratiivadverbidele.

\section{Keelematerjali analüüs}

Kuue lokatiivse demonstratiivadverbi (siit, siin, siia ning sealt, seal, sinna) esinemissagedused on esitatud tabelis 1 . Ruumisuhete märkimise järgi demonstratiivadverbe jagades võib näha, et kõige rohkem esineb materjalis ToImumisконтА väljendavaid (ehk lokatiivseid) adverbivorme siin ja seal (47,2\%). Sagedased on ka sІнтконтА märkivad (ehk latiivsed) vormid siia ja sinna (30,6 \%). LÄнтеконта kirjeldavate (ehk separatiivsete) adverbide siit ja sealt kasutusi on vähem $(22,3 \%)$. Natuke sagedasemad on vormid sealt, seal ja sinna, mida semantilises mõttes võib käsitleda kõnelejast kaugemale asukohale viitavate adverbidena.

Tabel 1.

Demonstratiivadverbide jaotus materjalis

\begin{tabular}{ccccccc}
\hline \multicolumn{2}{c}{ LÄHTEKOHA adverbid } & \multicolumn{2}{c}{ TOIMUMISKOHA adverbid } & \multicolumn{2}{c}{ SIHTKOHA adverbid } & \multirow{2}{*}{ Kokku } \\
siit & sealt & siin & seal & siia & sinna & \\
\hline $12(5,2 \%)$ & $\mathbf{3 9}(\mathbf{1 7 , 0} \%)$ & $31(13,5 \%)$ & $\mathbf{7 7}(\mathbf{3 3 , 6} \%)$ & $29(12,7 \%)$ & $\mathbf{4 1}(\mathbf{1 7 , 9} \%)$ & 229 \\
$51(22,3 \%)$ & \multicolumn{108}{c}{$(\mathbf{4 7 , 2} \%)$} & $70(30,6 \%)$ & $(100 \%)$ \\
\hline
\end{tabular}

Demonstratiivadverb esineb ainsa primaarselt ruumilist informatsiooni kandva mitteverbilise ühikuna umbes pooltes klausides $(\mathrm{n}=121 ; 52,8 \%$; vt tabelit 2). See tähendab, et peale verbi ja lokatiivse demonstratiivadverbi teisi ruumiväljendeid nendes klausides ei ole. 
Lokatiivsete demonstratiivadverbide esinemine liikumisklausides

\begin{tabular}{|c|c|c|c|c|}
\hline \multirow{2}{*}{$\begin{array}{l}\text { Demonstratiiv- } \\
\text { adverb }\end{array}$} & \multirow{2}{*}{$\begin{array}{l}\text { Ainukese ruumi- } \\
\text { väljendina }\end{array}$} & \multicolumn{2}{|c|}{$\begin{array}{l}\text { Kombinatsioonis mõne muu } \\
\text { ruumiväljendiga }\end{array}$} & \multirow{2}{*}{ Kokku } \\
\hline & & $\begin{array}{l}\text { Kõrvuti ruumi- } \\
\text { väljendiga }\end{array}$ & $\begin{array}{c}\text { Ruumiväljendist } \\
\text { eraldatuna }\end{array}$ & \\
\hline$\overline{\text { siit }}$ & $4(33,3 \%)$ & $5(41,7 \%)$ & $3(25 \%)$ & 12 \\
\hline sealt & $14(35,9 \%)$ & $10(25,6 \%)$ & $15(38,5 \%)$ & 39 \\
\hline siin & $18(58,1 \%)$ & $9(29 \%)$ & $4(12,9 \%)$ & 31 \\
\hline seal & $44(57,1 \%)$ & $21(27,3 \%)$ & $12(15,6 \%)$ & 77 \\
\hline siia & $21(72,4 \%)$ & $6(20,7 \%)$ & $2(6,9 \%)$ & 29 \\
\hline sinna & $20(48,8 \%)$ & $19(46,3 \%)$ & $2(4,9 \%)$ & 41 \\
\hline Kokku & $121(52,8 \%)$ & $70(30,6 \%)$ & $38(16,6 \%)$ & 229 \\
\hline
\end{tabular}

Süntaktiliselt on sellised kasutused tõlgendatavad kohamäärustena, mis annavad liikumiskirjeldusele ruumisemantilise mõõtme ning toimivad samaaegselt tekstisiseste viitevahenditena, olles samaviitelised kas eelnevas (vt näiteid 1 ja 2) või järgnevas diskursuses esitatud konkreetsema asukohafraasiga (vt näidet 3 ).

(1) Siis kadus ta veel lühikeseks viivuks kööki ning naasis sealt tikutoosi, pika küünla ja vanaaegse küünlajalaga. (IK)

(2) Igal aastal suundub sinna üha rohkem laevu ning räägitakse, et seal on rohkesti omavahelist sõdimist. (IK)

(3) Seal, kus tee metsast välja viis, voolas oja, mitte küll eriti lai, ent piisavalt kiirevooluline, et käivitada kloostri vesiveskit. (IK)

Ülejäänud klausides ( $\mathrm{n}=108 ; 47,2 \%$ ) esineb lokatiivne demonstratiivadverb kombinatsioonis mõne teise ruumiväljendiga (tüüpiliselt kohamäärusena funktsioneeriva nimisõnafraasiga, aga ka ruumilise tähendusega afiksaaladverbiga). On tavaline, et neil juhtudel paikneb demonstratiivadverb teisest ruumiväljendist ja ka verbist lauses vasakul. Ruumiväljendist vasakul on demonstratiivadverbi kasutatud 97 klausis (89,8 \%; vt näidet 4), paremal ainult kaheksas klausis (7,4 \%; vt näidet 5, kus adverbi asukoht võib olla tingitud adverbi funktsioneerimisest korrelaadina ning relatiivlause asukohast lause lõpus) ning kahe ruumiväljendi vahel kolmes klausis (2,8 \%; vt näidet 6$)$.

(4) „Aga kui me siin metsa all roomame, siis jätame ikka nõgeste kaitseks riided selga," lisas ta. (AK)

(5) Hea meelega oleks ta tagasi pöördunud sinna, kust oli tulnud. (IK)

(6) Ülemisele korrusele viiv trepp, mis suurest käsipidemenupust haarates veidi kääksub ja krigiseb, näeb välja nii, et sa kohe tajud neid hunnituid masse huvilisi, kes sama teed pidi enne sind sealt üles on marssinud. (AK)

Järgnev ülevaade kirjeldab demonstratiivadverbide kasutust eeskätt kombinatsioonides ruumiväljenditega, aga puudutab ka mõningaid muid teemasid. Esmalt kirjeldan demonstratiivadverbide ja ruumiväljendite koos- 
esinemiste tähenduslikke aspekte, lähtudes sellest, kas demonstratiivadverb ja ruumiväljend asetsevad kõrvuti või mitte. Seejärel vaatlen demonstratiivadverbe selle järgi, kas demonstratiiv paikneb ruumiväljendist klausis vasakul või paremal. Viimaks kirjeldan demonstratiivadverbide asetust klausis predikaadi suhtes ning adverbide jaotust verbide järgi.

\section{Demonstratiivadverbide ja teiste ruumiväljendite koosesinemised}

Kui klausis on kasutatud nii demonstratiivadverbi kui ka mõnda muud ruumiväljendit (selliseid klause on materjalis kokku 108), siis võib demonstratiivadverb esineda kas kõrvuti ruumiväljendiga $(\mathrm{n}=69 ; 64,8 \%)$ või eraldatuna teistest ruumiväljenditest ( $\mathrm{n}=39 ; 35,2 \%$; vt tabelit 3 ). Seejuures on semantiliselt võimalik, et kombinatsioonis mõne muu ruumiväljendiga väljendab demonstratiivadverb sama ruumisuhet kui teine ruumifraas klausis (sel juhul võime rääkida kongruentsest semantilisest funktsioonist; $\mathrm{n}=58 ; 53,7 \%$; vt näiteid 4 ja 7 ning 14 ja 15) või erinevat ruumisuhet (sel juhul on tegu inkongruentse kasutusega; $\mathrm{n}=50 ; 46,3 \%$; vt näiteid 10 ja 11 ning 17 ja 18). Kui klausis on mitu eri ruumisuhet tähistavat ruumiväljendit peale demonstratiivadverbi, võib kongruentsus jääda ebaselgeks, ent materjalis selliseid ebaselgeid juhtumeid ei esinenud. Kõigil juhtudel võib lokatiivne demonstratiivadverb olla kasutuses kas rohkem oma semantilises funktsioonis (ruumisuhte väljendajana) või rohkem tekstisisese viitesuhte hoidjana. Mõistagi oleks üsna keeruline määrata, milline funktsioon on parasjagu rohkem esil ning mil määral üldse kumbki neist funktsioonidest konkreetsel kasutusjuhul avaldub.

Tabel 3 .

Demonstratiivadverbide kombinatsioonid ruumiväljenditega

\begin{tabular}{lccc}
\hline \multirow{2}{*}{ Kongruentsus } & \multicolumn{2}{c}{ Lokatiivne demonstratiivadverb } \\
& $\begin{array}{c}\text { Kõrvuti teise ruumi- } \\
\text { väljendiga }\end{array}$ & $\begin{array}{c}\text { Eraldi teisest } \\
\text { ruumiväljendist }\end{array}$ & Kokku \\
\hline Kongruentne kasutus & $\mathbf{5 0 ( 4 6 , 3 \% )}$ & $8(7,4 \%)$ & $\mathbf{5 8 ( 5 3 , 7 \% )}$ \\
Inkongruentne kasutus & $20(18,5 \%)$ & $\mathbf{3 0}(\mathbf{2 7 , 8} \%)$ & $50(46,3 \%)$ \\
Kokku & $\mathbf{6 9}(\mathbf{6 4 , 8} \%)$ & $39(35,2 \%)$ & $108(100 \%)$ \\
\hline
\end{tabular}

On küllaltki ootuspärane, et kõrvuti asetsedes väljendavad demonstratiivadverb ja ruumiväljend pigem sama ruumisuhet (46,3\%), eraldi asetsedes aga pigem erinevat ruumisuhet $(27,8 \%$; vt tabelit 3$)$. Kui kõrvutisi inkongruentseid kasutusi esineb siiski pea viiendikus materjalis (18,5\%), siis mittekõrvutist ning samas kongruentset kasutust tuleb ette vaid üksikutel juhtudel $(7,4 \%)$. Demonstratiivadverbid siin, seal, siia ning eriti sinna on uuritavas materjalis kombinatsioonis ruumiväljendiga pigem kongruentse tähendusega, siit ja sealt on valdavalt kasutuses inkongruentselt (vt tabelit 4). Järgnevalt vaatleme kõiki nelja varianti ükshaaval. 
Lokatiivsete demonstratiivadverbide jaotus ruumiväljendiga ühildumise järgi

\begin{tabular}{|c|c|c|c|}
\hline $\begin{array}{l}\text { Demonstratiiv- } \\
\text { adverb }\end{array}$ & Kongruentne kasutus & Inkongruentne kasutus & Kokku \\
\hline siit & - & $8(100 \%)$ & 8 \\
\hline sealt & $4(16 \%)$ & $21(84 \%)$ & 25 \\
\hline siin & $8(61,5 \%)$ & $5(38,5 \%)$ & 13 \\
\hline seal & $21(63,6 \%)$ & $12(36,4 \%)$ & 33 \\
\hline siia & $6(75 \%)$ & $2(25 \%)$ & 8 \\
\hline $\operatorname{sinna}$ & $19(90,5 \%)$ & $2(9,5 \%)$ & 21 \\
\hline Kokku & $58(53,7 \%)$ & $50(46,3 \%)$ & 108 \\
\hline
\end{tabular}

Kõrvutist ja kongruentset kasutust ( $\mathrm{n}=50 ; 46,3 \%)$ näitlikustavad laused 4 ja 7 . Näites 4 (siin metsa all) on demonstratiivadverb siin kõrvuti kaassõnafraasiga metsa all ning näites 7 (sinna teerajaliiva) on sinna kõrvuti nimisõnafraasiga teerajaliiva, moodustades justkui ühe fraasi. Sellist kasutust võib võrrelda lisandi juhtumitega, kuna fraas metsa all täpsustab, millisele alale siin täpsemalt viitab, ning piiritleb selliselt ruumilise referendi (vt ka Pajusalu 2017a: 392-404). Samas täpsustab siin omakorda fraasi metsa all. Selles kombinatsioonis on demonstratiivadverbil määratleja roll (vt ka Pajusalu 2017a: 382-385) või kannab see koguni artikliga sarnaseid omadusi (vrd see mets; vt ka Pajusalu 1997, 1999: 64-65, 76-77). Sellises kasutuses näitab siin ühtlasi ka seda, et kõneleja asukoht langeb kokku ruumifraasiga metsa all väljendatud asukohaga, kusjuures diskursuses ei pea olema seda asukohta varem tutvustatud. Seevastu kõnelejast eemale viitav sinna näites 7 näitab, et kõneleja asukoht ei ole sama, mis ruumifraasiga kirjeldatud, samal ajal kui ruumifraasiga kirjeldatud asukoht (teerajaliiv) on diskursuses juba varem tutvustatud.

(7) Hesteri-oomen oli hõbedane raha, Ameerika pooldollar, mille leidsin ühel hommikul - lausa võimatu ette kujutada - oma Kivide aia jalgrajaliivast. [---] Kasutu oli tookord ja on ka praegu küsida, kust pudenes see Ameerika raha sinna teerajaliiva? (IK)

Võib arvata, et sellistel juhtudel on keelekõneleja jaoks tegu pigem ühe semantilise ühiku kui mitme ühiku summaga. Nii identifitseerivad demonstratiivadverbid nendes lausetes konkreetse ruumilise punkti ning demonstratiivadverbide kasutust võib interpreteerida artiklilaadse kasutusena (st nad märgivad definiitsust). Ühtlasi on võimalik, et demonstratiivadverbi ruumiline tähendus siiski kandub ka definiitsesse fraasi, mistõttu toob demonstratiivadverb identifitseeritud ruumiosa kõneleja ja kuulaja jaoks justkui lähemale (siin metsa all, vt näidet 4) või viib kaugemale (sinna teerajaliiva, vt näidet 7), kusjuures ilma demonstratiivadverbita muutuks oluliselt lause mõte, kuna kirjeldatav ruum oleks märgatavalt ebamäärasem, indefiniitsem (vrd aga kui me metsa all roomame; kust pudenes raha teerajaliiva). Neid tõlgendusi näib toetavat ka see, et kõrvuti asetsedes on lokatiivse demonstratiivadverbi 
ja ruumiväljendi kasutus pigem kongruentne, ent eraldi seistes on kasutus pigem inkongruentne (vt tabelit 3). Võib ka olla, et sellised kõrvutised ja kongruentsed kombinatsioonid varieeruvad kokkukuuluvustugevuse poolest, sõltudes fraasi pikkusest, komplekssusest, vormist ning muudestki teguritest.

Eraldi väärivad tähelepanu demonstratiivadverbide ja afiksaaladverbide koosesinemised. Afiksaaladverbid on eesti grammatikate käsitluses ühendverbide adverbilised komponendid ja moodustavad verbiga ühe terviku (EKG I: 33; EKG II: 21-22; Erelt 2017a: 60, 2017b: 104-107). Kui aga demonstratiivja afiksaaladverb satuvad kõrvuti, on tegelikult üsna raske määrata, kas valitseb tugevam kokkukuuluvus verbi ja afiksaaladverbi või demonstratiivadverbi ja afiksaaladverbi vahel. Ka ei saa enam rääkida demonstratiivadverbidest kui määratlejatest, kuna määratlejad peaksid kokku kuuluma nimisõnafraasiga (Pajusalu 2017a: 382-385). Näiteks lauses 8 on vormiliselt tegu ühendverbiga (sisse tungima), ent latiivse vormi sinna ning kõrvutise asetuse tõttu on partikkel sisse justkui kaassõna (vrd sinna sisse ja selle sisse, maja sisse). Ka näites 9 on raske eristada, kas olulisem on sõnade tuli ja tagasi või siia ja tagasi kombinatsioon.

(8) Hundid olid sinna sisse tunginud. (IK)

(9) Lits, kes mulle seda rääkis ütles, et ta tuli siia tagasi, kuna tahtis teada, kas minuga on ikka kõik korras. (IK)

Kõrvutine ja inkongruentne $(\mathrm{n}=20 ; 18,5 \%)$ kasutus tähendab seda, et demonstratiivadverb küll asetseb lauses ruumiväljendi kõrval, ent ei kirjelda sama ruumisuhet (siit lõuna suunas näites 10 ja seal pessa näites 11). Selliseid kasutusi iseloomustab demonstratiivadverbi semantiline n-ö iseseisvus (või ka suurem tekstisidususe ja väiksem ruumitähenduse kandmise funktsioon). Kuna ühildumist pole, ei saa ka rääkida demonstratiivadverbidest kui määratlejatest. Demonstratiivadverbi esinemine klausis koos teiste ruumiväljenditega on sellistes kombinatsioonides niisiis mõnevõrra juhuslikum kui eelmistes näidetes ning demonstratiivadverb on sellistes kombinatsioonides ruumifraasiga nõrgemalt seotud kui näiteks eespool kirjeldatud kongruentsetes kasutustes - demonstratiivadverb pigem ei moodusta teise ruumifraasiga fraasilist tervikut.

(10) Ent nii palju oli selge, et vankrid olid siit lõuna suunas veerenud. (IK)

(11) Jooksis mööda põllutaguseid kaasikuid Kalda heinaküüni ja puges seal pessa. (IK)

Demonstratiivadverbi ja afiksaaladverbi kõrvuti esinemise korral on ka eri ruumisuhete märkimisel mõneti raske hinnata, kas tugevamalt kuuluvad kokku afiksaaladverb ja verb või afiksaaladverb ja demonstratiivadverb. Olgugi et näidetes 12 ja 13 on vastavalt kasutusel ühendverbid ringi jalutama ning välja hüppama, on mõlemas näites verb adverbipaarist eraldatud muude lauseliikmetega (vastavalt adverbiaalidega ja subjektiga). See näib verbi ja afiksaaladverbi seotust nõrgendavat, samas kui adverbide kõrvuti asetsemine võib tekitada tunde, nagu kuuluksid kokku pigem need. 
(12) Mõtlesin, et jalutan natuke üksinda siin ringi ja siis poen põhku. (IK)

(13) Kui konn visata keevasse vette, siis hüppab ta sealt välja. (IK)

Eraldi ja kongruentseid kasutusi on materjalis üksikuid $(\mathrm{n}=8$; 7,4\%), kuigi eesti keel ilmselgelt lubab kasutada demonstratiivadverbi muust ruumiväljendist teiste lingvistiliste ühikute poolt eraldatuna, kusjuures demonstratiivadverb ja ruumiväljend väljendavad sama ruumisuhet, näiteks тогмuмisконтA, nagu näidetes 14 (sääl ... päiksepoolsel teeküljel) ja 15 (seal ... taamal), või siнтконта, nagu näidetes 5 (tagasi ... sinna) ja 16 (sinna ... ette). Laias laastus võib välja tuua kahesuguseid kasutusi. Ühel juhul, nagu näites 14, ei ole demonstratiivadverb ja ruumifraas täiesti samaviitelised, vaid demonstratiivadverb viitab ruumiliselt laiemale alale kui ruumifraas (ning toimib siinses lauses ka tugeva tekstisisese viitajana). Teisel juhul, nagu näites 15 , on demonstratiivadverb ja ruumifraas pigem samaviitelised ning demonstratiivadverb on tekstisisese viitamise funktsioonilt katafoorne.

(14) „Ilus, ilus on sääl põhjalas, ma näen vahel unes. Udu ja oktoobrivihmadki on sääl armsad,” ütleb tema. „Just neid ma igatsen siin leitsakus. Sääl kõnnin ma alati päiksepoolsel teeküljel, kõik kõnnivad. (IK)

(15) Seal ta jalutas taamal, mina omakorda ajasin ühe tuttava abituriendiga juttu ja teesklesin tähelepanematust. (IK)

(16) Tahtsin võtta siseraja, sinna lipsas Neumannova ette. (AK)

Omaette tasub taas välja tuua afiksaaladverbide ja demonstratiivadverbide koosesinemised ühes klausis (vt näiteid 5 ja 16), mispuhul ruumilise tähendusega afiksaaladverbi ja demonstratiivadverbi kokkukuuluvustugevust ilmsesti „nõrgendab” verbi ja afiksaaladverbi suurem seotus. Tasub siiski märkida, et verbilähedus annab ka demonstratiivadverbile arvatavasti suure seotuse verbiga.

Mittekõrvutine ja inkongruentne kasutus on siiski märksa sagedasem $(\mathrm{n}=30 ; 27,8 \%)$ kui mittekõrvutine ja kongruentne demonstratiivadverbi ja ruumiväljendi kombineerimine. Mittekõrvutine ja inkongruentne kasutus tähendab, et demonstratiivadverb ja ruumifraas viitavad eri ruumisuhetele, kusjuures demonstratiivadverbil on tugev tekstisisene (uurimuse materjalis ainult anafoorne) viitamise funktsioon. Lokatiivses tähenduses ehk TOIMUMISконтА väljendav demonstratiiv hõlmab sageli semantiliselt ka ruumifraasiga märgitud ruumi (vt näiteid 17 ja 18), samal ajal kui separatiivsed ja latiivsed demonstratiivadverbid märgivad ruumiosa, mis ei lange kokku ruumifraasiga märgitud ruumiosaga. Näiteks lauses 19 on kasutatud separatiivset vormi sealt ning SIнтKонтA väljendavat ruumifraasi oma koju, lauses 20 aga latiivset vormi siia ning LÄHTEKоHTA väljendavaid fraase Pärnust ja Tiiu juurest.

(17) Kuid ema ei lähe, jookseb ainult teisele poole teed, vajub seal oiates bussiootepingile kokku. (IK)

(18) Ta oli siin ainsana rongist väljunud. (IK)

(19) Ebaledes viis Joost õekesed nende talu kopli väravani, sealt suundus oma koju. (IK)

(20) Egas ta Pärnust Tiiu juurest ise siia ei lennanud! (IK) 
Afiksaaladverbide ja demonstratiivadverbide koosesinemised on üsna sarnased kõrvutiste kasutustega (vt näiteid 21 ja 22), ent võib arvata, et adverbid on siinsetes mallides omavahel mõnevõrra lõdvemalt seotud.

(21) Samas avanes köögikapi uks ja sealt puges välja nuhk. (IK)

(22) Oli seal päev otsa ringi kolanud ning kui me siis alles õhtul trehvasime, tunnistas ta, et ma saan nüüd aru küll, mis teid siin kinni peab. (AK)

\section{Demonstratiivadverbide asend lauses}

\subsection{Demonstratiivadverbi asend ruumiväljendi suhtes}

Lisaks eeltoodud mallidele saab lokatiivsete demonstratiivadverbide kasutust lauses iseloomustada ka teisiti, näiteks teistest lauseliikmetest lähtudes. Üks võimalus on vaadata demonstratiivadverbi asendit selle järgi, kas adverb asetseb ruumiväljendist lauses vasakul, paremal või hoopis kahe ruumiväljendi vahel.

Tabel 5 .

Lokatiivsete demonstratiivadverbide jaotus ruumiväljendi suhtes paiknemise järgi

\begin{tabular}{lrrrr}
\hline $\begin{array}{l}\text { Demonstratiiv- } \\
\text { adverb }\end{array}$ & $\begin{array}{c}\text { Ruumiväljendist } \\
\text { vasakul }\end{array}$ & $\begin{array}{c}\text { Ruumiväljendist } \\
\text { paremal }\end{array}$ & $\begin{array}{c}\text { Ruumiväljendite } \\
\text { vahel }\end{array}$ & Kokku \\
\hline siit & $\mathbf{7 ( 8 7 , 5 \% )}$ & - & $1(12.5 \%)$ & 8 \\
sealt & $\mathbf{2 3 ( 9 2} \%)$ & - & $2(8 \%)$ & 25 \\
siin & $\mathbf{1 3 ( 1 0 0 \% )}$ & - & - & 13 \\
seal & $\mathbf{3 2 ( 9 7 \% )}$ & $1(3 \%)$ & - & 33 \\
siia & $\mathbf{7 ( 8 7 , 5 \% )}$ & $1(12,5 \%)$ & - & 8 \\
sinna & $\mathbf{1 5 ( 7 1 , 4 \% )}$ & $6(28,6 \%)$ & - & 21 \\
Kokku & $\mathbf{9 7}(\mathbf{8 9 , 8} \%)$ & $8(7,4 \%)$ & $3(2,8 \%)$ & 108 \\
\hline
\end{tabular}

Kui demonstratiivadverb asetseb ruumiväljendist vasakul, on kõige tavalisem, et nad asetsevad kõrvuti ja väljendavad sama ruumisuhet, nagu käsitletud eespool ja näitlikustatud kombinatsiooniga siin metsa all (vt näidet 4 ja tabelit 5). Kui aga demonstratiivadverb asetseb ruumifraasist paremal, on demonstratiivadverbil (enamasti on selleks sinna) järellisandi omadusi, nagu näites 23, kus sinna (koos järgneva relatiivlausega) täpsustab seda osa metsast, kus kirjeldatav liikumine lõpeb. Ühtlasi toimib demonstratiivadverb sellistes lausetes korrelaadina (vt ka EKG II: 296-297). Sarnased kasutused iseloomustavad ka afiksaaladverbi ja demonstratiivadverbi kooskasutust, nagu lauses 24, kus kombineeruvad afiksaaladverb tagasi ja demonstratiivadverb sinna.

(23) Agrippa uuris hetke jõekääru ja siis suundusid nad edasi metsa, sinna, kust oli leitud põgenike hobune. (IK)

(24) Vic astub tagasi sinna, kus ta varem seisis. (IK) 
Ruumiväljendite vahel esineb demonstratiivadverb ainult kolmes lauses ning siis on nendeks demonstratiivadverbideks separatiivsed adverbid siit ja sealt, nagu näiteks lauses 6 sealt kombinatsioonis kaassõnafraasiga sama teed pidi ning afiksaaladverbiga üles.

\subsection{Demonstratiivadverbi asend predikaadi suhtes}

Veel üks võimalus on vaadata demonstratiivadverbi paiknemist verbi suhtes. Kombinatsioonidega klausides on verbist vasakul demonstratiivadverbi kasutatud 62 klausis (57,4\%; siin metsa all roomame näites 4$)$ ning verbist paremal 46 klausis (42,6 \%; jalutame sinna eemale näites 25). Samad proportsioonid on ka nende demonstratiivadverbide kasutuses, mis esinevad klausis üksi, ainsa ruumiväljendina: 72 klausis on demonstratiivadverb verbist vasakul $(59,5 \%$; siin kihutavad näites 26) ning 49 klausis verbist paremal (40,5\%; suundub sinna näites 2).

(25) „Jalutame sinna eemale, seal kivide peal on mõnus istuda, hästi ilus," tegi ta ettepaneku. (IK)

(26) Kõnnitee oli inimtühi, aga sõidutee oli veega kaetud ja siin $\underline{\text { kihutasid }}$ autod. (IK)

On iseloomulik, et kui demonstratiivadverb paikneb ruumiväljendist vasakul, paikneb ta ka verbist pigem vasakul, nagu näites 4 . Kui demonstratiivadverb paikneb ruumiväljendist paremal, paikneb ta suure tõenäosusega ka verbist paremal, nagu näites 25. See tähendab, et ruumiinfo esitatakse lauses pigem ühel pool verbi, kuigi võimalik on muidugi ka verbi asetus ruumiväljendite vahel. Kui vaadata demonstratiivadverbide vorme ja asetust verbi suhtes, siis on need just latiivsed adverbid siia ja sinna, mis verbist paremal esinevad (vt tabelit 6). Kuna verbi asukohta arvestav sõnajärg sõltub siiski paljudest faktoritest (lausetüübist, informatsioonistruktuurilistest faktoritest jpm; vt ka Tael 1988; Sahkai 1999; Lindström 2005), oleks demonstratiivadverbi ja verbi vastastikuse paiknemise analüüsi kindlasti vaja täiendada ka muude faktorite arvesse võtmisega, mis aga ei ole siinse uurimuse eesmärk.

Tabel 6 .

Lokatiivsete demonstratiivadverbide jaotus finiitvormis verbi suhtes paiknemise järgi

\begin{tabular}{lrcc}
\hline Demonstratiivadverb & Verbist vasakul & Verbist paremal & Kokku \\
\hline siit & $\mathbf{8}(\mathbf{6 6 , 7} \%)$ & $4(33,3 \%)$ & 12 \\
sealt & $\mathbf{2 7}(\mathbf{6 9 , 2} \%)$ & $12(30,8 \%)$ & 39 \\
siin & $\mathbf{2 1}(\mathbf{6 7 , 7} \%)$ & $10(32,3 \%)$ & 31 \\
seal & $\mathbf{5 0}(\mathbf{6 4 , 9} \%)$ & $27(35,1 \%)$ & 77 \\
siia & $14(48,3 \%)$ & $\mathbf{1 5}(\mathbf{5 1 , 7} \%)$ & 29 \\
sinna & $14(34,1 \%)$ & $\mathbf{2 7}(\mathbf{6 5 , 9} \%)$ & 41 \\
Kokku & $\mathbf{1 3 4}(\mathbf{5 8 , 5} \%)$ & $95(41,5 \%)$ & 229 \\
\hline
\end{tabular}




\subsection{Demonstratiivadverbid verbiti}

Viimaks tasuks mainida sedagi, et demonstratiivadverbide kasutus varieerub verbiti, mis on iseloomulik kõikidele ruumi väljendavatele üksustele (vt Taremaa 2017). On siiski tähelepanuväärne, et valimis olevatest verbidest suur osa (85 verbi 95 -st) esineb uurimismaterjali klausides koos lokatiivsete demonstratiivadverbidega. Ülekaalukalt kõige rohkem on demonstratiivadverbiga klause verbil käima $(\mathrm{n}=15)$, millele järgnevad ukerdama $(\mathrm{n}=9)$, tulema $(\mathrm{n}=8)$, purskama $(\mathrm{n}=7)$ ja suunduma $(\mathrm{n}=7)$. Verbiga käima esinevad liikumisklausides tavaliselt lokatiivsed vormid siin ja seal (vt näidet 27), vaid korra on kasutatud separatiivset vormi sealt (vt näidet 28). Miks just verb käima demonstratiivadverbidega sagedamini koos esineb, on siiski raske hinnata, seda osalt ka materjali vähesuse tõttu.

(27) Niisuguseid allikaid rahvas usaldab, varahommikuti käiakse seal kümblemas, kui on suvi. (IK)

(28) Vanasti olevat sealt Venemaa poolele käinud autoparv, midagi sellist, ilmselt, mida nägin Emajõel Kavastus. (IK)

\section{Kokkuvõte}

Liikumist väljendavate lausete näitel käsitletud lokatiivsed demonstratiivadverbid (siit, siin, siia ja sealt, seal, sinna) võivad olla kasutuses nii vormiliselt kui ka tähenduslikult üsna mitmel moel. Sageli on demonstratiivadverb liikumisklausis ainuke ruumiväljend peale liikumisverbi enda. Asendi järgi lauses võib lokatiivne demonstratiivadverb esineda nii kõrvuti ruumifraasi või afiksaaladverbiga kui ka teiste keeleüksuste poolt eraldatuna. Mõlemal juhul on tavalisem, et demonstratiivadverb paikneb neist teistest ruumiväljenditest vasakul. Teise ruumiväljendiga kõrvuti asetsedes viitab lokatiivne demonstratiivadverb pigem samale ruumisuhtele, eraldi asetsedes aga sagedamini erinevale ruumisuhtele. Predikaadi suhtes võib demonstratiivadverb samuti olla nii vasakul kui ka paremal, kusjuures esimene sõnajärg on uuritavas materjalis pisut sagedasem.

Igal demonstratiivadverbi vormil on ka eri tunnuste suhtes natuke erinev vormiline käitumine, mis viitab demonstratiivadverbide vormide eri funktsioonidele nii süntaktilises, pragmaatilises kui ka semantilises mõttes. On täheldatav, et demonstratiivadverbidel on teatud mustrites lisaks tekstisisesele, samaviitelisuse funktsioonile ka selge määratlev ja referenti identifitseeriv funktsioon, samuti annavad nad liikumiskirjeldustele liikumise algus-, toimumis- või lõpposa märkijatena olulise ruumilise tähenduse. Üldjuhul on siiski raske määrata, millised funktsioonid ning kui tugevasti igal konkreetsel juhul realiseeruvad. Näiteks on korpusmaterjali põhjal keeruline hinnata, kuivõrd kannab lokatiivne demonstratiivadverb mingites kontekstides ruumilist tähendust, kuivõrd aga talitleb definiitsusmarkerina. Üsna lahtiseks jääb ka see, kui tugevasti on demonstratiivadverbid eri kombinatsioonides ja mallides seotud teiste lauses esinevate ruumiväljenditega ning samuti klausis predikaadi funktsioonis oleva verbiga. 
Kirjutise valmimist on toetanud Euroopa Liit Euroopa Regionaalarengu Fondi kaudu (Eesti-uuringute Tippkeskus), see on seotud Eesti Haridus- ja Teadusministeeriumi uurimisprojektiga PUT701 „Referentsiaalsed vahendid eesti ja naaberkeeltes: eksperimentaalne lähenemine”. Tänan Renate Pajusalu ja anonü̈mset retsensenti, samuti Helen Hinti ja Maria Reilet artikli käsikirja lugemise ning asjalike kommentaaride eest.

\section{Kirjandus}

Clark, Herbert H., Schreuder, Robert, Buttrick, Samuel 1983. Common ground at the understanding of demonstrative reference. - Journal of Verbal Learning and Verbal Behaviour, kd 22, nr 2, lk 245-258.

Coventry, Kenny R., Valdés, Berenice, Castillo, Alejandro, GuijarroFuentes, Pedro 2008. Language within your reach: Near-far perceptual space and spatial demonstratives. - Cognition, kd 108, nr 3, lk 889-895.

Diessel, Holger 1999a. Demonstratives: Form, Function and Grammaticalization. (Typological Studies in Language 42.) Amsterdam-Philadelphia: John Benjamins Publishing.

Diessel, Holger 1999b. The morphosyntax of demonstratives in synchrony and diachrony. - Linguistic Typology, kd 3, nr 1, lk 1-50.

Diessel, Holger 2006. Demonstratives, joint attention, and the emergence of grammar. - Cognitive Linguistics, kd 17, nr 4, lk 463-489.

Dix o n, Robert M. W. 2003. Demonstratives: A cross-linguistic typology. - Studies in Language, kd 27, nr 1, lk 61-112.

EES = Eesti etümoloogiasõnaraamat. Peatoim Iris Metsmägi. Koost I. Metsmägi, Meeli Sedrik, Sven-Erik Soosaar. Tallinn: Eesti Keele Sihtasutus, 2012.

EKG I = Mati Erelt, Tiiu Erelt, Henn Saari, Ülle Viks 1995. Eesti keele grammatika I. Morfoloogia. Sõnamoodustus. Tallinn: Eesti Teaduste Akadeemia Eesti Keele Instituut.

EKG II = Mati Erelt, Tiiu Erelt, Henn Saari, Ülle Viks 1993. Eesti keele grammatika II. Süntaks. Lisa: kiri. Tallinn: Eesti Teaduste Akadeemia Keele ja Kirjanduse Instituut.

Enfield, Nick J. 2003. Demonstratives in space and interaction: Data from Lao speakers and implications for semantic analysis. - Language, $\mathrm{kd} 79$, $\mathrm{nr} 1$, lk 82-117.

Erelt, Mati 2000. On the pro-forms in Estonian. - Estonian: Typological Studies IV. (Tartu Ülikooli eesti keele õppetooli toimetised 14.) Toim M. Erelt. Tartu: Tartu Ülikool, lk 7-18.

Erelt, Mati 2017a. Sissejuhatus süntaksisse. - Eesti keele süntaks. (Eesti keele varamu III.) Toim M. Erelt, Helle Metslang. Tartu: Tartu Ülikooli Kirjastus, lk 53-89.

Erelt, Mati 2017b. Öeldis. - Eesti keele süntaks. (Eesti keele varamu III.) Toim M. Erelt, Helle Metslang. Tartu: Tartu Ülikooli Kirjastus, lk 93-239.

E relt, Mati 2017c. Liitlause. - Eesti keele süntaks. (Eesti keele varamu III.) Toim M. Erelt, Helle Metslang. Tartu: Tartu Ülikooli Kirjastus, lk 647-755.

Eslon, Pille 2014. Adverbi sisaldavate struktuuride tekstifunktsioonidest eesti ilukirjandus- ja õppijakeeles. - Lähivõrdlusi. Lähivertailuja, nr 24, lk 15-46.

Fillmore, Charles J. 1975. Santa Cruz lectures on deixis, 1971. Bloomington: Indiana University Linguistics Club. 
Fillm ore, Charles J. 1997. Lectures on Deixis. Stanford, California: CSLI Publications.

Gundel, Jeanette K., Hed berg, Nancy, Zach arski, Ron 1993. Cognitive status and the form of referring expressions in discourse. - Language, $\mathrm{kd} \mathrm{69,} \mathrm{nr} 2$, lk 274-307.

Halliday, M. A. K., Has an, Ruqaiya 2013. Cohesion in English. (English Language Series.) London-New York: Routledge.

Hint, Helen, R eile, Maria, $\mathrm{P}$ aj u s a l u, Renate 2013. Kontekst ja viitamine: argivestlused, legod ja narratiivid. - ESUKA/JEFUL, kd 4, nr 1, lk 161-183.

Kaiser, Elsi, Vihman, Virve 2010. On the referential properties of Estonian pronouns and demonstratives. - Memory, Mind and Language. Toim Hans Götzsche. Newcastle: Cambridge Scholars Publishing, lk 193-205.

Karmiloff-Smith, Annette 1979. A functional approach to child language: A study of determiners and reference. (Cambridge Studies in Linguistics 24.) Cambridge-New York-Melbourne: Cambridge University Press.

Ke evallik, Leelo 2011. Pro-forms as projective devices in interaction. - Discourse Processes, kd 48, nr 6, lk 404-431.

Ke m m erer, David 2006. The semantics of space: Integrating linguistic typology and cognitive neuroscience. - Neuropsychologia, kd 44, nr 9, lk 1607-1621.

La ury, Ritva 1997. Demonstratives in interaction: The emergence of a definite article in Finnish. (Studies in Discourse and Grammar 7.) Amsterdam-Philadelphia: John Benjamins Publishing Company.

Le u, Thomas 2008. The Internal Syntax of Determiners. New York University.

Levins on, Stephen C. 1983. Pragmatics. (Cambridge Textbooks in Linguistics.) Cambridge: Cambridge University Press.

Lindström, Liina 2005. Finiitverbi asend lauses. Sõnajärg ja seda mõjutavad tegurid suulises eesti keeles. (Dissertationes philologiae estonicae Universitatis Tartuensis 12.) Tartu: Tartu Ülikooli Kirjastus.

Li nd strö m, Liina 2017. Lause infostruktuur ja sõnajärg. - Eesti keele süntaks. (Eesti keele varamu III.) Toim Mati Erelt, Helle Metslang. Tartu: Tartu Ülikooli Kirjastus, lk 537-565.

Ly o n s, John 1977. Semantics. Kd I-II. Cambridge: Cambridge University Press.

Pajusalu, Renate 1997. Is there an article in (spoken) Estonian? - Estonian Typological Studies II. (Tartu Ülikooli eesti keele õppetooli toimetised 8.) Toim Mati Erelt. Tartu: Tartu Ülikooli Kirjastus, lk 146-177.

Pajus alu, Renate 1999. Deiktikud eesti keeles. (Dissertationes philologiae estonicae Universitatis Tartuensis 8.) Tartu: Tartu Ülikooli Kirjastus.

Pajusalu, Renate 2004. Tuumverbid ja deiksis. - Tuumsõnade semantikat ja pragmaatikat. (Tartu Ülikooli üldkeeleteaduse õppetooli toimetised 5.) Toim R. Pajusalu, Ilona Tragel, Ann Veismann, Maigi Vija. Tartu: Tartu Ülikooli Kirjastus, lk 53-61.

Pajusalu, Renate 2005. Anaphoric pronouns in Spoken Estonian: crossing the paradigms. - Minimal Reference - the Use of Pronouns in Finnish and Estonian Discourse. (Studia Fennica Linguistica.) Toim Ritva Laury. Helsinki: Finnish Literature Society, lk 107-134.

Pajusalu, Renate 2015. Võro demonstratives: changing or disappearing? - ESUKA/JEFUL, kd 6, nr 2, lk 167-190.

Pajusalu, Renate 2017a. Nimisõnafraas. - Eesti keele süntaks. (Eesti keele varamu III.) Toim Mati Erelt, Helle Metslang. Tartu: Tartu Ülikooli Kirjastus, lk 379-404. 
Paju s alu, Renate 2017b. Viiteseosed. - Eesti keele süntaks. (Eesti keele varamu III.) Toim Mati Erelt, Helle Metslang. Tartu: Tartu Ülikooli Kirjastus, lk 566589.

Peet er s, David, H a g o ort, Peter, Ö z y ür ek, Aslı 2015. Electrophysiological evidence for the role of shared space in online comprehension of spatial demonstratives. - Cognition, kd 136, lk 64-84.

Reile, Maria 2015. Space and demonstratives: an experiment with Estonian exophoric demonstratives. - ESUKA/JEFUL, kd 6, nr 2, lk 137-165.

Reile, Maria 2016. Distance, visual salience, and contrast expressed through different demonstrative systems: An experimental study in Estonian. - SKY Journal of Linguistics, kd 29, lk 63-94.

Sahkai, Heete 1999. Eesti verbifraasi sõnajärg. - Keel ja Kirjandus, nr 1, lk 24-32.

S a h kai, Heete 2003. Demonstrative doubling in Spoken Estonian. - Trames, kd $7, \mathrm{nr} 2$, lk 120-144.

Sahkai, Heete 2016. Demonstratives and information structure in spoken Estonian. - Information structuring of spoken language from a cross-linguistic perspective. Toim M. M. Jocelyne Fernandez-Vest, Robert D. Van Valin. BerlinBoston: De Gruyter Mouton, lk 211-235.

Soodla, Piret, Kirsipuu, Helen, Pajusalu, Renate 2012. Referentsiaalsed noomenifraasid laste narratiivides. - Eesti Rakenduslingvistika Ühingu aastaraamat, kd 8, lk 91-107.

Stevens, James, Zhang, Yang 2013. Relative distance and gaze in the use of entity-referring spatial demonstratives: An event-related potential study. - Journal of Neurolinguistics, kd 26, nr 1, lk 31-45.

Tael, Kaja 1988. Infostruktuur ja lauseliigendus. - Keel ja Kirjandus, nr 3, lk 133-143.

T a m m ekä nd, Liina 2015. Demonstratives in Võro and Estonian oral narratives. - ESUKA/JEFUL, kd 6, nr 2, lk 191-216.

T a r e m a a, Piia 2017. Attention meets language: a corpus study on the expression of motion in Estonian. (Dissertationes linguisticae Universitatis Tartuensis 29.) Tartu: University of Tartu Press.

Tauli, Valter 1973. Standard Estonian grammar. Part I: phonology, morphology, word-formation. (Acta Universitatis Upsaliensis. Studia Uralica et Altaica Upsaliensia 8.) Uppsala: Almqvist \& Wiksell.

Tauli, Valter 1983. Standard Estonian grammar. Part II: syntax. (Acta Universitatis Upsaliensis. Studia Uralica et Altaica Upsaliensia 14.) Uppsala: Borgströms Tryckeri AB.

Ve i s m a n n, Ann, E r elt, Mati 2017. Määrsõnafraas. - Eesti keele süntaks. (Eesti keele varamu III.) Toim M. Erelt, Helle Metslang. Tartu: Tartu Ülikooli Kirjastus, lk 416-429.

Veismann, Ann, Erelt, Mati, Metslang, Helle 2017. Määrus. - Eesti keele süntaks. (Eesti keele varamu III.) Toim M. Erelt, H. Metslang. Tartu: Tartu Ülikooli Kirjastus, lk 326-375.

Ve ski, Asta 1982. Eesti keele grammatika II. Määrsõna. Tartu: Tartu Riiklik Ülikool.

Vija, Maigi 2007. Pronoomenid lapsekeeles: mõnda mina ja sina omandamisest. - Eesti Rakenduslingvistika Ühingu aastaraamat, kd 3, lk 373-384. 


\section{The position and function of locative demonstrative adverbs in Estonian: a case study on motion clauses}

Keywords: locative demonstrative adverbs, reference, spatial semantics, syntax, motion, Estonian

Demonstratives are extremely important in all languages due to them having various pragmatic, semantic, and syntactic functions. For this reason, they are frequently studied and our current knowledge of demonstratives is also comparatively rich. However, research into demonstratives tends to concentrate mainly on demonstrative pronouns, while demonstrative adverbs have received much less attention. The same applies to Estonian linguistic tradition in that demonstrative pronouns are much more exhaustively investigated than demonstrative adverbs. The current study aims to fill this gap by analysing the use and function of locative demonstrative adverbs in Estonian. The analysis of locative demonstrative adverbs is based on 229 clauses that represent the semantic domain of actual motion (e.g., ta jooksis seal '(s)he was running there'). The analysis is primarily qualitative and focuses on the placement of demonstrative adverbs with respect to the other spatial expressions and the predicate in motion clauses. It also describes the syntactic, pragmatic, and semantic functions that demonstrative adverbs may have in discourse. The analysis reveals many patterns for Estonian locative demonstrative adverbs. Firstly, a demonstrative adverb in Estonian may be used as a single nonverb spatial expression in a clause (e.g., ta jooksis seal '(s)he was running there'), but it can also be used in combination with other spatial expressions (e.g., ta jooksis seal metsas 'lit. (s)he was running there in the forest'). Secondly, demonstrative adverbs tend to occur immediately before the spatial expression (see above), but they can also occur after the spatial expression (e.g., ta jooksis metsas seal '(s)he was running in the forest there'). Thirdly, they can be separated from the spatial expression by other syntactic units (e.g., seal ta jooksis metsas 'there (s)he was running in the forest'). Furthermore, when a demonstrative adverb and spatial expression are adjacent, they tend to refer to the same spatial region (e.g., ta jooksis sinna [GOAL] majja [GOAL] lit. '(s)he ran thereinto the house'). When they are not adjacent, they tend to refer to different spatial regions (e.g., seal [LOCATION] ta jooksis majja [GOAL] 'there (s)he ran into the house'). As for their syntactic functions, locative demonstrative adverbs can be described as locative adverbials, articles, or apposition-like units. They also help to create textual coherence and they clearly stand for many referential tasks, while also setting the spatial background of a depicted event. As such, the analysis of Estonian locative demonstrative adverbs indicates their rich and intricate structural and functional variability.

Piia Taremaa (b. 1982), PhD, University of Tartu, Research Fellow in General Linguistics, piia.taremaa@ut.ee 